\title{
COVID-19 and Hidden Housing Vulnerabilities: Implications for Health Equity, New Haven, Connecticut
}

\author{
Alana Rosenberg ${ }^{1} \cdot$ Danya E. Keene ${ }^{2} \cdot$ Penelope Schlesinger ${ }^{1} \cdot$ Allison K. Groves $^{3} \cdot$ Kim M. Blankenship $^{4}$
}

Published online: 24 May 2020

(c) Springer Science+Business Media, LLC, part of Springer Nature 2020

COVID-19 has laid bare our connectedness, with early maps demonstrating its movement from person to person and community to community. But over time, the maps have revealed a darker truth, exposing vast inequality and shameful rifts within societies, exemplified in the case of the United States. One such dimension of inequality impacting the pandemic is housing. Our research on housing as a social determinant of HIV risk reveals understudied and neglected housing vulnerabilities that may impact COVID-19 risk.

The concept of "household" is key to COVID-19 because our current best defense against the virus is social distancing, a household level strategy. Policy makers have recognized that those without a household are at risk: COVID19 responses, although likely inadequate in many places, have included assistance for people who are homeless. One such response has been contracting with now empty hotels to provide rooms for people without residences, so they can observe social distancing guidelines [1]. Leaseholders have also been included in COVID-19 responses, with temporary forgiveness of late rental payments (though these plans include many caveats) [2]. These responses, however imperfect, do little for those with less visible but often highly insecure housing arrangements. Traditional dichotomies of housed versus homeless, or even stably versus

Alana Rosenberg

alana.rosenberg@yale.edu

1 Department of Epidemiology of Microbial Diseases, Yale School of Public Health, Yale University, 60 College Street, New Haven, CT 06520, USA

2 Department of Social and Behavioral Sciences, Yale School of Public Health, Yale University, 60 College Street, New Haven, CT 06520, USA

3 Department of Community Health and Prevention, Dornsife School of Public Health, Drexel University, Nesbitt Hall, 3215 Market Street, Philadelphia, PA 19104, USA

4 Department of Sociology, American University, 4400 Massachusetts Ave, Washington DC, NW 20016, USA unstably housed, do not adequately capture the varied housing arrangements in low income communities.

Through the Justice, Housing and Health Study (JustHouHS) we examine housing vulnerability and mass incarceration to document how they operate and intersect to impact health, with a specific focus on HIV risk. 400 low income residents of predominantly minority neighborhoods in New Haven, CT, half recently released from prison, completed biannual surveys about housing, criminal justice history and health between 2017 and early 2020. Fifty-four participants also participated in in-depth qualitative interviews. These data have deepened our understanding of housing vulnerability. The term "household" takes on different meanings when housing scarcity and community ties create webs of shifting units of people living together, from temporary stays to lifelong arrangements, and from homeowners to renters, to those with no legal ties to the place they stay.

Many of our participants struggle regularly, or even daily, in their quest for housing; nonetheless, they are not considered homeless because they neither stay in shelters nor live on the streets. They are 'housed,' albeit precariously. For example, while over $30 \%$ reported homelessness in the last 6 months, more than half of those were homeless for only part of that time. Many of them were among the nearly three quarters of participants who reported ever having lived or stayed with someone to avoid being homeless. Brandon, an African American man in his late fifties, represents just one example. During the 3-year JustHouHS study period, he stayed at different shelters until settling most recently at his sister's house. As with Brandon, participants' residences changed regularly: $66 \%$ responded that there was a $50 \%$ or greater chance that they would not be living in the same place in 6 months. People moved between multiple households in their social network to avoid overstaying their welcome, and in response to changing social ties. For example, many male participants returning from prison or leaving a halfway house, sober house, or treatment program found temporary shelter at girlfriends', sisters' or parents' 
homes, going in between households as circumstances changed. Tom, an African American man in his late forties and a native of New Haven, landed a full-time job at a recycling plant, but his criminal record prevented him from securing his own housing. To lessen the burden on any one household, he split his time between his father's place and the home of his daughter's mother, with whom he had maintained a friendship after their partnership ended.

Conversely, the more stably housed within the JustHouHS sample often felt obligated to provide shelter to those relatives, friends, and partners locked out of housing due to low wages, unstable employment, or failed criminal background or credit checks. A quarter of respondents in the most recent JustHouHS survey said that in the last 6 months, they let someone stay with them because they had no place to go. For example, Rayna, an African American woman in her early forties with five children, housed her daughter, her daughter's partner, and her daughter's child at different points during the study period. Her daughter's family would stay in a shared space such as the living room, or in a room with one of Rayna's four sons. Brooklyn, also African American in her early forties, now lives in a one bedroom apartment with two of her adult sons. Although tenuously housed herself throughout the study period, moving several times, she always prioritized having a place where her adult sons could stay when they had no other options.

Such housing situations have implications for the social distancing recommended to stem the COVID-19 pandemic. For some people who are precariously housed, social distancing as one household unit can require a dramatic change in living arrangements, necessitating living at only one place. Efforts to comply with social distancing guidelines may strain or upend close relationships within or outside of the household, negatively impacting mental and physical health. For other people, living in only one household isn't possible due to childcare, elder care, and other multiple household situations. Even with efforts to carefully follow recommendations to the best of their ability, people may be placed at increased risk, along with all those in their housing network. Since such networks are located in areas where many residents have similar arrangements, the risk for entire communities may be elevated.

For those that house others, the financial, personal and health risks they take on in doing so will likely be exacerbated by COVID-19. At the same time, the pandemic, the public health response to it, and its aftermath will likely increase the need for community members to provide housing to others: as homeless shelters close, more people are released from incarceration due to the virus, economic opportunities are scarce or non-existent, and housing opportunities are increasingly limited.
It did not take long for the race inequities in COVID-19 infection, hospitalization and death rates to become apparent [3, 4], and though harder to document, it seems clear that poor communities are disproportionately impacted as well. We seek to understand these inequities by applying what we have learned through JustHouHS about how social determinants of health impact on race inequities in HIV. Housing vulnerability, criminal justice involvement, complicated histories of medical mistrust and disparate healthcare treatment all combine to render people of color at increased risk for HIV. These same social determinants of health are now implicated in the inequities increasingly documented in COVID-19 infections, hospitalizations and death.

In the next phase of our research, we hope to focus on how housing vulnerability creates inequities in the pandemic's impacts. While many of those studying health inequities have long understood the connection between housing vulnerability and health, we will focus on an oft-overlooked group of the housing vulnerable-the precariously housed and their hosts. We aim to document and analyze how this group is impacted by the virus and the public health response to it. Our hope is that the crisis brought on by the COVID-19 pandemic will expand public discussion of the critical need to rethink our entire approach to housing - to see safe and affordable housing as a critical social good and fundamental right for all. And, as we work to translate that awareness into new policies and programs, we will do so in ways that recognize the many different forms that housing vulnerability can take.

\section{References}

1 Kim C. It took a pandemic for cities to finally address homelessness. 2020. https://www.vox.com/2020/4/21/21227629/coronaviru s-homeless-covid-19-las-vegas-san-francisco. Accessed $30 \mathrm{Apr}$ 2020.

2 The Eviction Lab. COVID-19 housing policy scorecard. 2020. https://evictionlab.org/covid-policy-scorecard/. Accessed $30 \mathrm{Apr}$ 2020.

3 Artiga S, Orgera K, Pham O, Corallo B. Growing data undercore that communities of color are being Hardr Hit by COVID-19. 2020.https://www.kff.org/coronavirus-policy-watch/growing-dataunderscore-communities-color-harder-hit-covid-19/. Accessed 30 Apr 2020.

4 Centers for Disease Control and Prevention. COVID-19 in racial and ethnic minority groups. 2020. https://www.cdc.gov/coron avirus/2019-ncov/need-extra-precautions/racial-ethnic-minorities .html. Accessed 30 Apr 2020.

Publisher's Note Springer Nature remains neutral with regard to jurisdictional claims in published maps and institutional affiliations. 